\title{
HVMANITAS
}

\section{Tradición clásica y voluntad política en el Setenario de Alfonso X El Sabio}

\section{Autor(es): $\quad$ López Rodríguez, Concepción}

Publicado por: Faculdade de Letras da Universidade de Coimbra, Instituto de Estudos

URL

persistente: URI:http://hdl.handle.net/10316.2/27520

DOI: $\quad$ DOI:http://dx.doi.org/10.14195/2183-1718_61_8

Accessed : $\quad$ 26-Apr-2023 09:45:58

A navegação consulta e descarregamento dos títulos inseridos nas Bibliotecas Digitais UC Digitalis, UC Pombalina e UC Impactum, pressupõem a aceitação plena e sem reservas dos Termos e Condições de Uso destas Bibliotecas Digitais, disponíveis em https://digitalis.uc.pt/pt-pt/termos.

Conforme exposto nos referidos Termos e Condições de Uso, o descarregamento de títulos de acesso restrito requer uma licença válida de autorização devendo o utilizador aceder ao(s) documento(s) a partir de um endereço de IP da instituição detentora da supramencionada licença.

Ao utilizador é apenas permitido o descarregamento para uso pessoal, pelo que o emprego do(s) título(s) descarregado(s) para outro fim, designadamente comercial, carece de autorização do respetivo autor ou editor da obra.

Na medida em que todas as obras da UC Digitalis se encontram protegidas pelo Código do Direito de Autor e Direitos Conexos e demais legislação aplicável, toda a cópia, parcial ou total, deste documento, nos casos em que é legalmente admitida, deverá conter ou fazer-se acompanhar por este aviso. 
humanitas

\section{Vol. LXI}

IMPRENSA DA UNIVERSIDADE DE COIMBRA

COIMBRA UNIVERSITY PRESS 


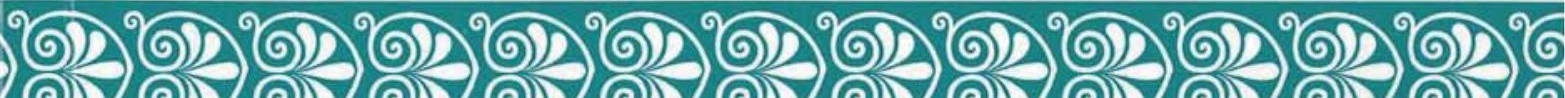

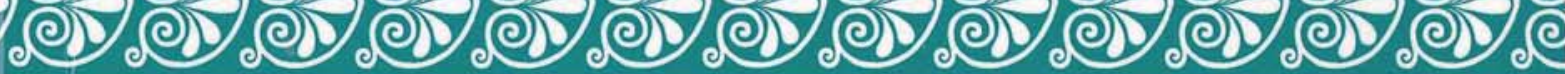

Vol. LXI 


\title{
TRADICIÓN CLÁSICA Y VOLUNTAD POLÍTICA EN EL SETENARIO DE ALFONSO X EL SABIO
}

\author{
Concepción López Rodríguez y Pedro Redondo Reyes \\ Universidad de Granada \\ clopez@ugr.es
}

\begin{abstract}
The Castilian King, Alphonso X the Wise, wrote the Setenario following different classical traditions that have given to the seven number one symbolical meaning. This value comes from many Greek and Latin authors; one of them, perhaps the most important, is Ptolemy. But Alphonso found out how to fit perfectly that traditional symbol to his proper work providing it with a religious and political content; furthermore he made of this number the emblem of his proper name: in Spanish language, in fact, A-l-f-o-n-s-o has seven letters. On the other hand, these letters summarize his personal excellence. But, mainly, his final purpose is essentially political: he aims to unify his kingdom which was scattered into different local laws after the Reconquest.
\end{abstract}

Keywords: Classical Tradition, Alphonso X, Setenario, Astrology, Ptolemy.

\section{Resumen}

El rey castellano, Alfonso X el Sabio, compuso la obra del Setenario siguiendo diversas tradiciones clásicas que otorgaban al numero siete un valor simbólico; este valor proviene de muchos autores griegos y latinos; uno de ellos, quizás el más importante, es Tolomeo. Pero Alfonso supo adaptar este símbolo a su propia obra, dotándola de un contenido religioso y político; también hizo de este número el emblema de su propio nombre: en castellano A-l-f-o-n-s-o tiene siete letras. Estas letras, desde otra perspectiva, resumen su excelencia personal, pero, sobre todo, su propósito final es esencialmente político: aspira a unificar su reino que estaba disperso jurídicamente en leyes locales después de la Reconquista.

Palabras clave: Tradición Clásica, Setenario, Alfonso X, Astrología, Tolomeo. 
Dentro del marco de la producción literaria de Alfonso X el Sabio y de su entorno de colaboradores aparece esta singular obra del Setenario, la cual ha sido objeto de variada interpretación por parte de la crítica ${ }^{1}$, no muy abundante por cierto. Al leer sus páginas observamos que inmerso en el oscuro entramado de sus palabras emerge, entre otros, un componente que podemos definir como de "herencia clásica" o "tradición clásica".

Es nuestra intención exponer y demostrar con la mayor eficacia posible la utilización que el rey Alfonso X hace de este material heredado. No se trata, en modo alguno, de llevar a cabo un exhaustivo análisis de cada elemento, noción o palabra cuyos antecedentes pertenezcan a la cultura de Grecia y Roma -ello nos obligaría a elaborar un verdadero tratado cuyo formato alcanzaría las páginas de un extenso libro-; se trata más bien de captar la funcionalidad del elemento "clásico" en esta obra y de precisar sólo aquellos referentes que resulten reveladores del punto de vista aquí planteado.

${ }^{1}$ La edición que utilizamos como base de este estudio es la llevada a cabo por Vanderford, K. H. (1984), Alfonso el Sabio, Setenario. Barcelona: Editorial Crítica. En realidad, esta edición del texto es la misma que el autor llevó a cabo en 1945 en Buenos Aires. Reproducida íntegramente con posterioridad, se completa con un estudio preliminar de Rafael Lapesa.

Convendría recordar aquí la descripción que Martínez Marina hace del Setenario: "El libro Setenario, según le disfrutamos hoy, se puede dividir en dos partes: en la primera, que viene a ser una especie de introducción añadida por don Alonso el Sabio, se trata difusamente de varias cosas notables, comprehendidas en el número siete, como de siete nombres de Dios; de los siete dones del Espíritu Santo; de siete virtudes del rey don Fernando; de siete perfecciones de la ciudad de Sevilla; de las siete artes liberales; de los siete planetas; y otras de esta naturaleza. La segunda abraza las mismas materias de la primera Partida; pero no llega más que hasta el sacrificio de la misa. Comienza por un tratado de la Santa Trinidad y fe católica, con cuyo motivo se trata de la idolatría y errores de los gentiles, de la naturaleza de los astros que ellos adoraban, y de los signos del zodíaco: van a continuación las leyes de los sacramentos, muy pesadas y difusas". Cf. Martínez Marina, F. (1808), Ensayo histórico-crítico sobre la antigua legislación y principales cuerpos legales de los reynos de León y Castilla, especialmente sobre el código de D. Alonso el Sabio, conocido con el nombre de las Siete Partidas. Madrid. Vanderford (Op. cit., 26) recoge las palabras arriba citadas y le presta gran atención a las opiniones de Martínez Marina porque "percibió todo el significado de la obra". 
Una cuestión previa resulta principio obligado de nuestro particular análisis: la determinación, breve y esquemática, de la época y condiciones socio-culturales en las que se compuso este tratado. Hemos de partir no de la figura del propio rey Sabio sino de su padre, Fernando III.

Kenneth H. Vanderford en la introducción a la edición del Setenario alude precisamente a las circunstancias previas a la elaboración del mismo y dice $^{2}$ :

El hecho es que, si bien el reinado de Fernando fué de los más afortunados, la situación general de su reino, en el orden legislativo, dejaba mucho que desear. La explicación, según la concebía su hijo y sucesor, Alfonso X (1252-1284), era clara:

"Fuero dEspana antiguamiente en tienpo de los godos fue todo uno. Mas quando moros ganaron la tierra, perdiéronse aquellos libros en que eran escriptos los fueros. E después que los christianos la fueron cobrando, así como la yvan conquiriendo, tomavan de aquellos fueros algunas cosas segunt se acordavan, los unos de una guisa e los otros de otra. E por esta razón vino el departimiento de los fueros en las tierras".

En el texto citado aparecen en negrita dos conceptos básicos (uno y departimiento) a los que se debe prestar atención: "El código visigodo del Forum judicum que había dado unidad legislativa a la España premusulmana, se mantuvo generalmente como ley común del país, pero pocos fueros (territoriales, provinciales...) hubo que no lo derogaran en pormenores". Es decir: no existía una norma jurídica clara y diferenciada que sirviera como soporte legislativo para regir el panorama de unas tierras que en su mayoría -salvo el reino de Granada- habían sido conquistadas a los moros. Se necesitaba, pues, una unidad jurídica que cohesionara toda la dispersión surgida tras la Reconquista.

El rey Fernando ideó un gran proyecto que, sin embargo, no pudo llevar totalmente a cabo. Es verdad que en la primera fase del mismo colaboraron padre e hijo pero, finalmente, fue Alfonso por encargo de Fernando el que terminó esta labor iniciada por ambos. El Setenario constituye una parte -tal vez previa- de la plasmación de esa empresa. El propio rey Sabio lo comenta en las primeras páginas de su obra ${ }^{3}$ :

Et por ende cató (se refiere al rey Fernando, su padre) que lo meior e más apuesto que puede sser era de fazer escriptura en que les demostrase

\footnotetext{
${ }^{2}$ Cf. K. Vanderford, Op. cit., 14.

${ }^{3}$ Cf. Setenario, 23.
} 
aquellas cosas que auyan de fazer para sser buenos e auer bien, e guardarse de aquellos que los ffiziesen malos por que ouyesen a ffazer mal. Et esta escriptura que la ffiziessen e la touysen así commo heredamiento de padre e bienffecho de señor e commo conseio de buen amigo. Et esto que ffuese puesto en libro que oyesen a menudo, con que se costunbrasen para sser bien acostunbrados, e que sse affiziesen e vsasen, rraigando en sí el bien e tolliendo el mal. Et que lo ouyesen por ffuero e por ley conplida e çierta e por que ouyese a toller de los coraçones siete cosas en que errauan los que eran entonçe por desentendimiento. Et teníe que erraríen más ssi ante non ssopiesen cómmo sse auyan a guardar.

\begin{tabular}{|c|c|c|c|c|c|c|}
\hline $\begin{array}{c}\text { POR } \\
\text { MAN- } \\
\text { CEBÍA }\end{array}$ & $\begin{array}{c}\text { POR MAL } \\
\text { ENTENDI- } \\
\text { MIENTO }\end{array}$ & $\begin{array}{c}\text { POR MAL } \\
\text { CONSEIO }\end{array}$ & $\begin{array}{c}\text { POR OLVI- } \\
\text { DANÇA }\end{array}$ & $\begin{array}{c}\text { POR NON } \\
\text { RREÇE- } \\
\text { BIR CAS- } \\
\text { TIGO }\end{array}$ & $\begin{array}{c}\text { POR } \\
\text { VILEZA }\end{array}$ & $\begin{array}{c}\text { POR } \\
\text { DESME- } \\
\text { SURA }\end{array}$ \\
\hline
\end{tabular}

Tiene razón, en parte, Amador de los Ríos ${ }^{4}$ cuando define el Setenario como una especie de catecismo político, moral y religioso; lo entiende a la manera de "una preparación moral para el libro de leyes que meditaba". Esta segunda parte del argumento del mencionado estudioso nos parece menos exacta porque entendemos que la moralidad presente en las páginas del Setenario está supeditada a un interés puramente político, con lo cual pierde esencia ética aunque se observen diversas consideraciones al respecto.

La estructura del libro aparece articulada en torno al número siete, como hemos podido constatar en el casillero anteriormente expuesto, herencia pitagórica consciente e intencionadamente asumida, como en su día ya señaló Manuel Rodríguez ${ }^{5}$, entre otros, indicio claro de la voluntad cultural integradora que preside la tarea de Alfonso X en este libro. Una de las ambiciones fundamentales del gran Rey Sabio es dar cohesión y unidad a las tierras que están bajo su dominio; esa cohesión y unidad, cuya última

${ }^{4}$ Cf. De los Ríos, A. (1863), Historia crítica de la literatura española. Madrid, 483.

${ }^{5}$ Este autor, al hablar del "elogio" que el rey Alfonso dedica a su padre al comienzo del Setenario, dice: "Hállase al principio de un tratado, que intituló don Alonso "Septenario", sin duda porque, preciándose su autor de filósofo, abrazó la idea de dividir en siete miembros o partes todo cuanto iba tratando en períodos separados; lo que demuestra que el método pitagórico era algo del genio y gusto poco fino de este Rey". Vid. De Manuel Rodríguez, M. (1800), Memorias para la vida del rey don Fernando III, Madrid, 217. 
y más importante escala es la política, contiene sin embargo otros elementos auxiliares de gran trascendencia que vinculados al primer elemento -el interés político- dotan a la propuesta de Alfonso $\mathrm{X}$ de una riqueza inigualable. El autor pretende unificar bajo la fe cristiana los elementos de creencias ajenas a la misma y las reintegra en el cristianismo, llevando a cabo una inteligente labor sincrética porque no rechaza de modo taxativo, no condena ni desprecia los elementos ajenos a su fe, sino que en la mayoría de las ocasiones los justifica por la ignorancia. En palabras de Rafael Lapesa $^{6}$, para Alfonso X, "el paganismo idólatra era falso, pero vislumbraba de manera inconsciente algo de la creencia verdadera"; de ahí que se proponga como nuevo iluminador de las tinieblas, abriendo los ojos a aquellas gentes que por no haber sabido encontrar al Dios verdadero adoraron a ídolos o veneraron a elementos de la naturaleza como el agua, el fuego, el aire o la tierra, o se entregaron a cultivar la astrología como una especie de religión, con sus preceptos zodiacales. Pero, por algo se conoce en la historia a Alfonso X como rey sabio; captó como ninguno el poder aglutinador de la cultura: él no sólo alude al pasado con un interés puramente religioso de redención de "Gentiles" sino como fuente de cultura. Se sirve del patrimonio cultural heredado, sobre todo de Grecia, y, por decirlo de alguna forma, lo venera. No son para él los sabios de la antigüedad meros idólatras. Cuando le interesa cita sus doctrinas y sus nombres, excluyéndolos en parte de la mera calificación de "gentiles". Resulta admirable por ello su labor, por integradora y coherente; resulta también admirable y ambicioso, como seguidamente veremos, su empeño: en realidad, él quiere erigirse como un nuevo tipo de monarca que aglutina su misión política, integrando bajo su dominio el poder de la iglesia con su doctrina y apareciendo ante todos como el detentador de la más alta sabiduría.

El desarrollo de su programa empieza con la exposición de las razones del título y la justificación de la estructuración del mismo. De hecho la Ley I, que constituye el inicio del Setenario ${ }^{7}$, tal y como ha llegado hasta nosotros, está enunciada de la siguiente forma:

${ }^{6}$ Rafael Lapesa (1984), “Estudio Preliminar”, in K. H. Vanderford, Op. cit., 10.

${ }^{7}$ El Setenario es una obra que no ha llegado completa hasta nosotros. Según declara Rafael Lapesa, "Todo contribuye a producir extrañeza. La falta de los primeros folios, una importante laguna al final de la Ley XI y el haber quedado, al parecer, inacabado hacen que sea difícil reconocerle un plan". Vid. Op. cit., 7. 
[Ley.- De las ssiete letras de Alpha et O que muestran cada una ssiete nonbres de Dios $^{8}$ ]

En Isidoro de Sevilla también se aprecia una descripción similar, con la diferencia bien significativa de que la descripción define el movimiento que se contiene en el Señor de principio a fin como de la A hasta la $\Omega$ y no desde la A hasta la o (letra castellana), que es la propuesta de Alfonso X.

Partiendo, pues, de este número siete, en primer lugar aplicado a siete letras, inicia su recorrido haciendo derivaciones todas con el número siete como eje de articulación. Dice así:

A es la quarta letra de Alpha e muestra otras ssiete nonbres de Dios en latín, que sson éstos:

\begin{tabular}{|l|l|l|l|l|l|l|}
\hline AURORA & ARTIFEX & AURA & AUXILIUM & AGNUS & ANGULUS & ALTARE \\
\hline
\end{tabular}

Onde el nonbre de Aurora, que quiere decir por la lunbre que viene quando aluoreçe ante que ssalga el ssol...

Naturalmente sigue comentando todos los términos encuadrados otorgándoles una explicación particular. Como se aprecia, y como él mismo declara, en esta ocasión pertenecen a la lengua latina aunque alguno, como aura ("brisa"), sea de procedencia griega.

Interesante resulta también el despliegue que nos ofrece el Rey Alfonso partiendo de la letra $\mathrm{T}$ que asimismo muestra siete nombres de Dios; son estos:

\begin{tabular}{|l|l|l|l|l|l|l|}
\hline THEOS & ATHINUO & THETICA & THETRAGAMATON & THITAM & THIPUS & THELON \\
\hline
\end{tabular}

${ }^{8}$ En Isidoro de Sevilla (Etym. 1,3,9) se lee: Concurrentibus enim in se invicem A ad $\Omega$ usque devolvitur, et rursus $\Omega$ ad A replicantur, ut ostenderet in se Dominus et initii decursum ad finem et finis decursum ad initium ("En un movimiento de concurrencia mutua, la A se desarrolla hasta la $\Omega$ y ésta, a su vez, se repliega hasta la A; y así, el Señor muestra que en el se contiene todo movimiento de principio a fin y de fin a principio"). También dice Isidoro que los griegos tenían entre sus letras místicas la T, que es una de las letras que según Alfonso X dice contiene los nombres de Dios.

Por otra parte, la Patrística en alguna ocasión afirma que precisamente "siete" es el nombre de Dios, por ejemplo Ireneo (precisamente al hilo de los siete

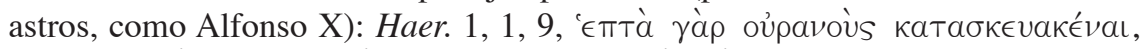

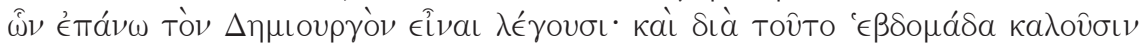
àvTóv. 
Para no entrar en un análisis pormenorizado de cada uno de ellos, aludiremos solamente a dos porque muestran claramente el uso que hace Alfonso X de la terminología griega; con respecto a Thetragamaton ${ }^{9}$ comenta: En griego quiere dezir nombre de Dios ascondido, e por esto, porque algunas gentes lo nonbrauan por ssennal de letras, e non por uoz; porque teníen que lengua de omne mortal non era digna de nonbrar a él nin ponerle nonbre ssennalado. Esta denominación, que es frecuente en escritores judíos, presenta un paralelo con Filón de Alejandría como ponemos en evidencia en nota a pie de página. Desde otro punto de vista, también resulta muy curiosa la asimilación que lleva a cabo entre Titán: sol: Dios ${ }^{10}$. Lo explica de la siguiente manera: Titan es nonbre del ssol, e por esso le llamaron a Dios porque él ffaze nasçer e creçer todas las cosas, assí commo el ssolffaze por el poder e por la vertud que él le dió. Tenemos aquí un procedimiento constante en su obra: la incorporación de elementos paganos al patrimonio de las virtudes de Dios sobre los que en definitiva manda pues, según manifiesta, este sol-Titán ejerce su dominio sobre la naturaleza por el poder que el propio Dios le otorgó. En el fondo la recurrencia a la terminología latina y griega, no analizada o analizada certera o incorrectamente responde a un afán científico y a un intento de dignificar culturalmente su tratado; desde este punto de vista el mundo greco-latino es contemplado con considerable reverencia y aludido como elemento indiscutible de autoridad. Ello no quiere enmascarar en absoluto la idea recurrente en el tratado de que este mundo pertenecía a lo que él

${ }^{9}$ El Tetragrámaton como nombre de Dios y la imposibilidad de ser pronunciado u oído se lee en los escritores judíos, y también en los cristianos de lengua griega; al final es un locus communis. Un ejemplo de paralelo con Alfonso X es el pasaje de Filón de Alejandría, Vida de Moisés 2, 114, 2 ss. Cohn, ò [scil.

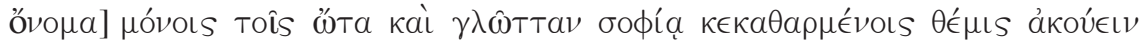

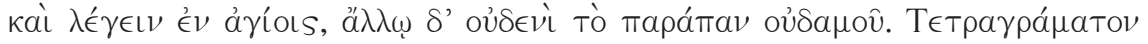

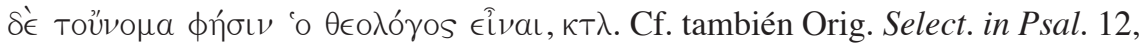
1104, 9; Clem. Alex. Strom. 5, 6, 34; Eus. Gen. elem. Intr. 15, 19, etc.

${ }^{10}$ Parece que aquí Alfonso X lo que hace es llevar a un término cristiano una identificación entre Titán y el sol que aparece ya antes en Isidoro de Sevilla, Etym. 8, 11, 53: Apollinem quamvis divinatorem et medicum vellent, ipsum tamen etiam Solem dixerunt, quasi solum. Ipsum Titan, quasi unum ex Titanis, qui adversus Iovem non fecit ("Aunque sostienen que Apolo es adivino y médico, dijeron que también era el sol, como si dijera "él solo”, pues fue -siendo Titán- el único de los Titanes que no se rebeló contra Júpiter”). 
denomina "sacrílego". Ambas ideas son consonantes en el texto: eran sacrílegos en sus creencias religiosas pero culturalmente merecen ser incorporados porque constituyen una parte de la historia y, desde un punto de vista más restringido, contaron con grandes figuras sobre todo en el campo de la filosofía.

Continúa el Rey Sabio con su constante labrado en siete. Y dice: $L a$ letra $O$ es la ssetena letra de que ssalen otros ssiete nonbres con que llaman los omnes a Dios. Y estos ssiete son de bueltas de letras de todos lenguaies destos sobredichos, que son griego e ebraico e latín:

\begin{tabular}{|l|l|l|l|l|l|l|}
\hline OSANNA & OROS & ORTOS & OXI & OLOCAUSTOMA & OMNIPOTENS & ODA \\
\hline
\end{tabular}

Alfonso interpreta cada una de las denominaciones que otorga a Dios siguiendo un criterio etimológico que a continuación, en algunos casos, brevemente comentamos:

Oros: quiere decir "visión de paz". Se trata de un sustantivo creado a partir de una palabra griega que guarda parentesco etimológico con el verbo horao, que significa "ver".

Ortos: quiere decir "derecho". Dios es "recto" y hace que sean "rectos" todos los que a él se acercan. Palabra de origen griego.

Oxi: define Alfonso esta cualidad de Dios con el adjetivo "acuçioso"; hace las cosas cuando entiende que conviene que sean hechas. Es un adjetivo de origen griego cuya raíz significa "agudo". Si en las dos anteriores denominaciones (Oros, Ortos) el caso del nominativo masculino singular acabado en -os correspondía perfectamente a su transliteración griega, en este caso, Alfonso no transcribe del griego un nominativo singular en $-u s$ sino la terminación de la desinencia neutra en $-u$. Rasgos descriptivos de este tipo, a veces erróneos en algún sentido, se pueden encontrar a lo largo del tratado, como sucede en el caso que a continuación citamos.

Olocaustoma: quiere decir que Dios es recibidor del sacrificio que hacen por las almas de los muertos, perdonándoles sus pecados. Este término también corresponde a un neutro griego terminado en - ma. La voz griega es holocautoma, sin la -s, significa "holocausto", sacrificio en el que la víctima era consumida enteramente por el fuego.

Omnipotens: quiere decir que Dios es poderoso en todas las cosas y que es Dios "conplidamente". En este caso Alfonso utiliza un adjetivo de origen latino y así lo hace saber. 
Como se puede apreciar, Alfonso aquí ha tomado del griego la mayoría de las definiciones de los atributos de Dios, no dejando a un lado ni el hebreo, al que acude en primer lugar con su Osanna, ni el latín con su Omnipotens.

Una vez que ha llegado al final de las definiciones en esta Ley I de las letras desde la Alpha a la $\mathrm{O}$ y de sus correspondientes subclasificaciones, siempre en siete, dice:

Onde la A con rrazón demuestra, ssegunt de ssuso dixiemos, que Dios es comienço, et la O ffin; non porque Dios ouo comienço en ssí nin puede sser acabado, mas porque él da comienço e acabamiento a todas las cosas que él ffizo.

Culmina esta Ley, y ello es lo más interesante desde nuestra tesis, con lo que supone la equiparación del propio nombre de Alfonso (que empieza por A y termina en O) a la figura anteriormente definida de Dios:

Et por ende nos don Alffonso... cuyo nonbre quiso Dios por la ssu mercet quiso que sse començasse en A e sse ffeneciese en $O$..., a ssemeiança del ssu nonbre. Por estas ssiete letras enbió ssobre nos los ssiete dones del Spíritu Ssanto, que sson éstos: Spíritu de Ssaber, Spíritu de Entendimiento, Spíritu de Conseio, Spíritu de Ffortaleza, Spíritu de Seso, Spíritu de Piedat, Spíritu de Temor de Dios... ... Et por la vertud destos spíritus quiera él que este libro que nos començamos por mandado del rrey don Ffernando, que ffué nuestro padre naturalmiente e nuestro sennor, en cuyo nonbre, ssegunt el lenguaie de Espanna, ha ssiete letras.

Parece claro que el verdadero carácter tan debatido de este libro se refleja en estas primeras palabras; no es un tratado filosófico, no es una obra puramente histórica, no es sólo una exposición de carácter religioso; es, sobre todo, un panegírico del rey Fernando (cuyo nombre, según comenta en el texto arriba citado, tiene siete letras: $F E R A N D O$ ) y del propio Alfonso; es un tratado, en última instancia, político o de encomio con finalidad política porque los sacramentos y los omnipresentes elementos de la fe cristiana funcionan bajo el dominio de la voluntad políticamente integradora del rey que utiliza como vehículo la Ley de Dios y la doctrina de la Iglesia.

Continúa Alfonso X exponiendo otras razones que le llevaron a titular su obra con el nombre de Setenario:

[Ley XI.-] Setenario pusiemos nonbre a este libro porque todas las cosas que en él sson van ordenadas por cuento de siete. Et esto ffué porque es más noble que todos los otros ${ }^{11}$... .... que ssale de ssiete rrazones.

${ }^{11}$ La idea de la excelencia del número siete está en las fuentes griegas y 
A una de estas siete razones, a la sabiduría concretamente, pertenece la astrología junto a otras seis; para Alfonso X, la astrología sse alcança por catamiento e por vista ${ }^{12}$, et es la quinta arte destas ssiete e ffabla de los çielos porque sson llamados en latín astra. E ésta es partida en ssiete maneras:

\begin{tabular}{|c|c|c|c|c|c|c|}
\hline $\begin{array}{c}\text { POR } \\
\text { VISTA }\end{array}$ & $\begin{array}{c}\text { POR } \\
\text { ENTENDI- } \\
\text { MIENTO }\end{array}$ & $\begin{array}{c}\text { POR } \\
\text { [OBRAS] }\end{array}$ & $\begin{array}{c}\text { POR } \\
\text { MUDAMIENTO }\end{array}$ & $\begin{array}{c}\text { POR } \\
\text { CUENTA }\end{array}$ & $\begin{array}{c}\text { POR } \\
\text { MEDIDA }\end{array}$ & $\begin{array}{c}\text { POR } \\
\text { ACOR- } \\
\text { DANÇA }\end{array}$ \\
\hline
\end{tabular}

Onde la primera, que es por vista, ffaze connosçer las siete estrellas que llaman planetas; cada una en quál çielo está e cómmo sse mueue en dos guisas: la una, en ssu çielo; la otra, en ssu çerco apartado...

Naturalmente el saber de la Astrología que aparece alineado en esta casilla de la sabiduría junto a la Gramática, Lógica, Retórica, Música, la

romanas por doquier. Un ejemplo latino clásico es Aulo Gelio (NA 3, 10, 1-2) citando a Varrón, $M$. Varro in primo librorum, qui inscribuntur hebdomades vel de imaginibus, septenarii numeri, quem Graece hebdomada appellant, virtutes potestatesque multas variasque dicit ("M. Varrón comenta las muchas y variadas virtudes y poderes del número siete, llamado por los griegos "hebdomadas", y añade: facit etiam stellas, quas alii "erraticas", P. Nigidius "errones" appellat. Circulos quoque ait in caelo circum longitudinem axis septem esse ("también da lugar a las estrellas que otros llaman "errantes" y P. Nigidio "errones". Dice también que siete son en el cielo los círculos que rodean el eje en toda su longitud"); esto es un antecedente de la referencia a los siete planetas de Alfonso X. Cf. ibidem 3, 10,16 .

Más tardíamente y en un autor cristiano-hispano hallamos referencias similares sobre el número siete, en general: cf. Isidoro de Sevilla, Etym. 6, 17, 17: ...propter ipsum numerum septenarium, quo universitatis significatio saepe figuratur; qui etiam ipsi Ecclesiae tribuitur instar universitatis, etc. (“...es debido al mismo número siete, con el que a menudo se representa el concepto de universalidad y que, por su misma universalidad, se aplica también a la Iglesia misma"). Cf. ibidem 8, 1,3.

${ }^{12}$ En la astrología y astronomía grecorromanas, los criterios de discernimiento eran la vista (=aisthesis, opsis) y la razón (=nous, logos, "catamiento"). En Tolomeo, modelo de cualquier especulación posterior, razón y percepción están descritos en sus funciones en su opúsculo Sobre el criterio y el principio rector (8, 13.11 Lamm.; cf. Arist. De An. 432 5 ), una propedéutica para la actividad astronómica posterior, entre otras. 
Física y la Metafísica, ocupando el quinto lugar, está supeditada al conocimiento de Dios:

Onde por estos ssiete ssaberes a que llaman artes ssopieron los omnes connosçer a Dios e a todas las cosas que él fizzo, quáles son en ssí e cómmo obran. Et aun por ellas ssopieron los ssiete çielos en que están las siete estrellas a que llaman planetas, e los nonbres de cada una dellas. Et déstos ssacaron los cuentos de los días de la semana e nonbraron a cada uno ssegunt el nonbre de ssu planeta. Et partieron el día e la noche por oras e por grados e por puntos ${ }^{13}$ e por otros cuentos tan menudos que sse entienden más por entendimientos de omne que por vista. Et ssopieron otrossí partir las ssemanas por meses, e los meses por annos, e los annos por tienpos, e los tienpos por edades. Et ssegunt aquello partieron la rredondez del çielo en ssiete partidas. Et fezieron otrosí ssiete de la tierra que está en ssu derecho, tan bien yermo commo poblado, a que llaman en lenguaie griego as climas, que quiere tanto dezir commo logares ssennalados en que ha cada una de las planetas ssu sennorio e muestran y ssu vertud.

Et esto mismo ffizieron a los ssiete metales ${ }^{14}$, que sson éstos:

\begin{tabular}{|l|l|l|l|l|l|l|}
\hline ORO & PLATA & ARGENTE BIVO & COBRE & FFIERRO & ESTANNO & PLOMO \\
\hline
\end{tabular}

Que a cada uno pusieron nonbre ssegunt la planeta qu auya poder ssobrél, assí commo oro, el ssol, porque es linpio e ffermoso e noble más que los otros metales. Et la plata, a la luna...

La huella de Tolomeo, al que menciona más tarde y de manera expresa, concretamente en la Ley LXVII, se deja percibir en la concepción astrológica de nuestro rey, tanto en la división astronómica del día por

${ }^{13}$ La división astronómica del día la efectúa Tolomeo en Almagesto, 2, 9 (horas, grados, etc.). En este tratado se estudia la cronología y los calendarios. Cf. Toomer, G. J. (1998), Ptolemy Almagest. Princeton: University Press, 12 ss.). Las "ssiete partidas" que dividen el cielo son los siete círculos constituidos por el ecuador, los polos y los trópicos, cf. Ptol. Alm. 2, 6 ss.

Los climas (una noción astronómica, cf. Cleomed. 18, 21) también fueron presentados por Tolomeo en su obra astrológica Tetrabiblos $(2,2)$, pero la división de la Tierra en siete climas procede de época helenística: vid. Posid. Fr.3 (=Strab. I 1 13). Cf. Neugebauer, O. (1975), A History of Ancient Mathematical Astronomy, Berlin-Heidelberg-Nueva York, vol. 1, 334 ss., 2, 727 ss.

${ }^{14}$ Sobre la enumeración de los siete metales se pueden citar como probables fuentes Isid. Etym. 16, 17 y, antes, Hieron. Comm. Agg. 2 (25, 1404 M). 
horas, grados..., teoría presente en Almagesto, como en las "siete partidas" que dividen el cielo correspondientes con los siete círculos constituidos por el ecuador, los polos y los trópicos; también Alfonso X recoge del sabio griego la concepción de "los climas", presentes en Tetrabiblos. Además, consciente el propio rey castellano de esta deuda importantísima, titula la mencionada ley de esta manera: [Commo Tolomeo fabla altamiente en fecho de astrología, assí ffizo Sant Johan en las propiedades de Dios]. Al margen del título, esta Ley XVII comienza con un elogio del filósofo griego y con apreciaciones que son dignas de mención porque muestran una vez más la integración y la superación mediante la fe cristiana de creencias anteriores a la misma:

Tolomeo ffué uno de los grandes philosofos que nunca ouo en la arte de astrología; ca éste ffabló más alto en fecho de los çielos et de las estrellas que otro que ffué. Et departió más de cosas en ffecho de las planetas e de loss signos que otro; ca ffué omne que entendió e punnó en saber más de las poridades de los cielos.

Tras el elogio de una tan eminente figura, el rey Alfonso introduce la paralela en el mundo cristiano no desacreditando la imagen del astrónomo pagano sino estableciendo una similitud en el quehacer de los dos personajes:

Et aquella carrera misma touo Sant Iohán euangelista entre los apóstolos e los otros ssantos; ca así commo Tolomeo ssiguió la manera de las crençias antiguas que creyen las gentes, assí Sant Iohán siguió otrosí las maneras de las crençias neuas de Ihesu Cristo. Et sopo tanto de las poridades que ouo de ffazer libro, que llaman Apocalipsi, que quiere dezir en griego visiones marauillosas de los secretos de Dios. E este libro es partido por cuento de siete e de doze, en que mostró el cuento derecho de las siete planetas uerdaderas e de los doze signos.

De las obras atribuidas a Tolomeo dos resultan particularmente interesantes como fuentes principales de las nociones astronómicas-astrológicas del Setenario:

- Almagesto o Sintaxis Matemática, distribuido en 13 libros; es el gran tratado de astronomía.

- Tetrabiblos o Quadripartitum, que, según Robbins ${ }^{15}$, debería de ser con toda probabilidad el Tratado Matemático en cuatro libros. Su contenido es de astrología.

${ }^{15}$ F. E. Robbins, en su edición y traducción del Tetrabiblos de Claudio Tolomeo, dice: "Though the Tetrabiblos enjoyed almost the authority of a Bible 
Hemos de tener en cuenta que, en el tiempo de Tolomeo, los términos "astronomía" y "astrología" coincidían en su sentido: ambas eran astronomía y, además, desde la época helenística, la astrología incluso era considerada como ciencia; en cambio, "matemática" (o, como el título griego de este tratado tolemaico, apotelesmatiká) indicaba más exactamente lo que hoy conocemos como astrología.

La presencia de las teorías tolemaicas en el tratado de Alfonso X es, al margen de un hecho declarado por el propio autor, fácilmente perceptible incluso en aquellos lugares que no lo declara. Por ejemplo, la noción de "climas" o la división del día. Así el autor griego titula un capítulo de su

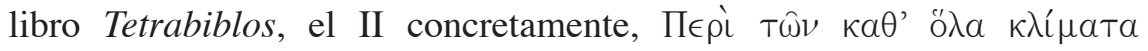

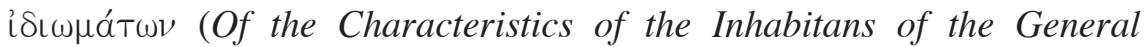
Climes $\left.^{16}\right) \mathrm{y}$, como se ha citado en su momento, también Alfonso X habla de la noción de "climas". Pero, quizás el hecho más interesante porque atañe a la concepción misma del saber astronómico-astrológico de los dos autores es la incorporación al mismo del cálculo matemático. El constante empleo de los números obedece tanto en Tolomeo como en su seguidor Alfonso X al propósito de presentar sus ideas con el carácter de una ciencia. Quizás en esto nos parece de mayor sinceridad las teorías del sabio griego y mucho más políticamente intencionada la propuesta del rey castellano.

Dejando a un lado la interesante y vastísima relación entre Claudio Tolomeo y el Rey castellano, nos centraremos en un pasaje que revela de forma singular la presencia y la función del mundo antiguo, especialmente el griego, considerándolo desde un punto de vista estrictamente religioso. $\mathrm{Si}$ a lo largo de las páginas del Setenario tenemos oportunidad de leer muchas veces, y de presentir otras tantas, adaptaciones alfonsinas de teorías astrológicas y astrológico-etnográficas de fuente griega autorizada como la que acabamos de exponer en el caso de Tolomeo, ahora, sin embargo, el rey castellano generaliza y engloba bajo el criterio de Sectas Idólatras de laAntigüedad toda una serie de nociones, también plagadas de connotaciones astrológicas, algunas de las cuales merecen citarse.

among the astrological writers of a thousand years or more, its Greek text has been printed only three times...". Vid. Robbins, F. E. (2001), Ptolemy. Tetrabiblos. Harvard: University Press, 11 . Muchos de los manuscritos lo citan con el título Tà

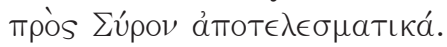

${ }^{16}$ Vid. Tetrabiblos 2, 2 (Robbins). Los "climas" son un factor determinante en la configuración de los pueblos que hace Tolomeo en su Geografía, así como en su Almagesto (cf. I 1, p.18 Heib.). 
Con el gusto por su criterio etimológico y erudito, Alfonso X parte de la noción de Secta:

[Ley XII].- Qué quier dezir secta.

Secta tanto quiere dezir commo cosa departida de otra. Et por ende aquellos que creen las cosas luengas e enoiáuansse de la longura dellas, et apartauan una partida quanto entendian que podría abondar a su poco entendimiento. E atal crençia commo ésta llaman secta.

Con la idea, pues, establecida de que secta quiere decir una parcela del conocimiento de una cosa y con el añadido de los criterios opinión, antoiança, fantasía, ssuenno, visión, instrumentos todos ellos parciales o engañosos de un saber verdadero, Alfonso prosigue exponiendo las razones y las circunstancias de aquellos que "adoraban" a los cuatro elementos, doctrina como sabemos presente en los filósofos presocráticos griegos. El Rey parece dirigirse en este contexto a un público que necesita una sencilla explicación de la teoría presocrática de los cuatro elementos (tierra, agua aire y fuego), de forma tal que la expresa muy poco científicamente utilizando criterios de un saber cotidiano accesible a las personas menos ilustradas pero, al mismo tiempo, quiere dejar constancia de su saber universal al aludir a ellas y tratar de superarlas mediante la conclusión, que expresa de manera anticipada en la Ley XVIII (De cómmo no deue omne aorar sinon a Dios solo) de que el hombre debe adorar sólamente a Dios. A modo de ejemplo citamos las palabras que Alfonso X dedica a los que adoraban al elemento tierra:

[Ley XIX].-De los que adorauan la tierra.

Tierra es el primer helemento, que quier dezir tierra dura e sseca ssobre que andan todas las animalias. Et a ésta aorauan primero algunas gentes por ssu entendimiento, que era tal que pues de la tierra nasçíen todas las cosas de que los omnes biuien e todas las otras animalias, e a la tierra tornauan e ella las desffazíe después que murien e en natura della sse conuertíen, que les era assí commo madre e por nascençia e por criança e por ssepultura, e por ende que a ella deuyan aorar e non al.

La ruta que conducía hasta la época de Alfonso X en cuanto al conocimiento de esta teoría, no la conocemos por ahora con certeza, sí podemos avanzar la hipótesis de que se sirviera de las alusiones aristotélicas a la misma o tal vez de Clemente de Alejandría, fundador de la Escuela Catequística quien en sus obras, bien en su Protéptico o en sus ocho libros de los Stromata, introdujo comparaciones entre el paganismo y el cristianismo junto a frecuentes citas de poetas y filósofos griegos. Sea cual sea la 
fuente directa está claro que el origen es griego, en concreto procede de los filósofos presocráticos, como se ha dicho, si bien ellos mismos en muchos casos habrían tenido influencias orientales. ${ }^{17}$

En Alfonso X se produce con respecto a la teoría presocrática de los primeros principios un curioso cambio de matiz, los remitifica a su estilo; así el agua no es sólo un elemento sino que dando un paso hacia atrás la concibe deificada al estilo del Océano homérico o también, podríamos decir, que interpreta de manera literal las palabras de unos autores que se referían en ocasiones a estos elementos con nombres de dioses, pero con el conocimiento de que hablaban metafóricamente.

Después de referirse a esta Secta, Alfonso X introduce en la Ley XXIII otra que agrupa bajo el título De los que se aorauan unos a otros. Bajo este rótulo comenta: Et por esto sse aorauan unos a otros en tal manera que ssi algún enperador o rrey era bienjusticiero en ssu vida, llamáuanle dios de justiçia... Et esso mismo ffazíen de las mugieres, que ssi alguna era buena o casta de ssu cuerpo, llamáuanla la deessa de voluntad. Tal teoría corre paralela, si no es una referencia cierta, a la tradición evemerista $^{18}$. Evémero en sus escritos aludía a una isla, la isla de los panqueos, en el Océano Índico, en la que el propio autor había encontrado una estela de oro con noticias sobre Urano, Cronos y Zeus. En este documento descubrió que los dioses, cuando no poderes de la naturaleza personificados, eran simplemente hombres de grandes merecimientos del remoto pasado. Ennio se encargó de divulgar esta doctrina entre los romanos y llegó a alcanzar tal notoriedad que ya el evemerismo se ha convertido en una forma de entender la religión. A ella creemos que hace referencia Alfonso en esta Ley, en la que además dice que en una fase posterior dexaron de aorar los bivos e aorauan los muertos que murieron sseyendo buenos. Et por rremenbrança dellos ffazían ymágines ssegunt ssu figura, que aorauan... Et esto duró muy grant tiempo, ffasta que vieron que non tenía pro, pues que vieron que todo sse auya a destroyr; ca los biuos muríen e los muertos sse desffazíen. Et por ende partiéronse desta ffantasía.

${ }^{17}$ Para una visión completa de las teorías de los cuatro elementos resulta de gran utilidad la lectura de la conocida obra de Kirk, G. S. y Raven, J. E., (1979), Los filósofos presocráticos. Madrid: Gredos.

${ }^{18}$ Vid. Lesky, A. (1976), Historia de la literatura griega. Madrid: Gredos, 812. 
Una vez expuesta la anterior teoría llegamos a un punto muy interesante dentro de las Sectas Sacrílegas de la Antigüedad con respecto al tema que nos ocupa y que introduce en la Ley XXIV:

[Ley XXIV].- De cómmo el sonnar ffazía a los omnes caer en grandes yerros.

... porque tan afficadamiente ssuennan que aquello que veen en ssuennos, tienen que es verdat... Et ouo y algunos omnes antigos que ssonnauan que ssubían a los çielos e que veyen los ángeles e que ffablauan con ellos, e que les mostrauan creençias por que podrían connosçer a Dios. Por esso sse tornaron a creer que los çielos eran Dios por la grandeza e por la claridat e por la ffermosura que en ellos veyen. E creyendo en ellos, adoráuanlos e ffazíanles sacriffiçios de cosas que quemauan e olyen bien, creyendo que aquel ffumo que ssubya allá e que lo rrecibían aquellos spíritus que estauan en los çielos. Et parando mientes a esto, ffallaron por cuenta ssegunt les ssemeió, que eran ssiete çielos, e pusieron a cada uno ssu nonbre. Et nonbraron otrossí los ángeles que los guardauan, et dixieron que eran ssiete. Et estudieron muy grant tiempo, ffasta que catando en ellos, vieron que en cada uno de aquellos cielos auya una estrella. Et cada una dellas auya ssu mouymiento apartadamiente ssegunt el ssu çielo. Et vieron que aquellas estrellas auyan cuerpos más nobles que los çielos, e por esso tornaron a creer en ellas.

Y dice a continuación en la Ley XXV, que se titula De las planetas:

Planetas pusieron nombre los ssabios antigos a estas ssiete estrellas que pussiemos en la ley ante désta... dixieron que auyan poder ssobre ssiete cosas, assí commo ssobre los elementos et ssobre las animalias e ssobre las plantas, et ssobre las mineras, e ssobre los tienpos, e ssobre las edades, e ssobre las vidas ${ }^{19}$.

La doctrina astrológica del poder de los siete astros sobre las circunstancias humanas tiene su locus classicus en el Tetrabiblos de Tolomeo donde se explican los poderes e influencias de los planetas, así como sus naturalezas benignas o malignas.

${ }^{19}$ Igualmente Tolomeo dedica un capítulo de su Tetrabiblos al poder de los planetas, concretamente el punto cuarto de su libro primero, al margen claro está de consideraciones presentes en toda su obra y de manera especial en la parte que continúa a este capítulo cuarto y hasta el séptimo. El título de este capítulo cuarto

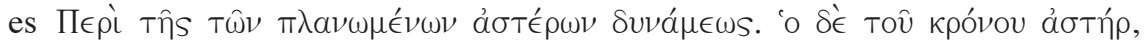
traducido por Robbins (Op. cit., 35) como Of the Power of the Planets. 
Seguidamente comenta las propiedades de estos siete planetas, que en realidad no son siete sino cinco: Mercurio, Venus, Marte, Júpiter, Saturno, a los que añade el Sol y la Luna. No es original Alfonso X en esta distribución planetaria, sino que de nuevo acudimos como fuente primera a Pitágoras, al que probablemente le corresponda y está relacionada con su teoría de la armonía de las siete esferas en analogía con la lira de siete cuerdas. Pero, por encima de estos siete cielos los antiguos se dieron cuenta de que había un octavo cielo donde estaban las estrellas que se encuentran más cerca de Dios; y comenzaron a adorar a aquellas figuras de estrellas a las que pusieron el nombre de signos: Aries, Tauro, Gémini, Cangreio, León, Virgo, Libra, Scorpio, Sagitario, Capricornio, Aquario y Pisçis. Termina diciendo [Ley XXXIII]: Et por más auya llegar a ssaber la virtud que auyen, partieron estos xii ssignos a los quatro elementos. Et dieron a cada un elemento tres; es decir, los distribuyeron por signos de agua, aire, fuego, tierra, de tres en tres. Mas a estos ssignos (Ley XXXIV) no les dauan annos assennalados, nin mes, nin ssemana, nin día, nin hora, nin puntos, nin grados...Ante partíen estos ssignos por ellas, dando a cada una planeta dos, ffueras que dieron a la luna e al ssol ssennos. Et el ssigno que dieron a la luna por ssu casa es [Cangreio]. Et los dos ssignos que dieron al Mercurio son Gémeni e Virgo ${ }^{20} \ldots$... En este punto Alfonso X también menciona de pasada otras creencias como cuando habla de los que adoraban a la Cabeza del Dragón. Pero, Todas estas antojanças (Ley XXXV) e setas e opiniones que auemos dicho en la ley ante désta, e otras maneras que no podríen ser contadas fazíen a los omnes errar, e non sabíen connosçer a Dios ni creyen en él como deueíen... E ésta es creençia a la fee e la ley derecha de Nuestro Sennor Ihesu Cristo, que non fué tomada de los elementos, que se dannan, mezclándose unos con otros, nin los siete çielos, do estauan las planetas que han sus mouimientos a vezes delante, a vezes atrás, nin del otauo cielo, que es figurado de estrellas menudas, segunt auemos dicho; mas fué tomada del nono, que es sobre todos los otros, segunt dixeron los filósofos e los sabios antiguos. E mostraron por su saber que aquél era lugar e morança de Dios; porque aquel çielo non se mouíe e fazíe mouer todos los otros, asy commo Dios non se mиеие e fas mouer todas las cosas de nada...

${ }^{20}$ Cf. Ptol. Tetr. 1, 17, “Finalmente dieron a Mercurio... los signos restantes,

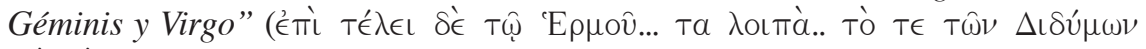
каi то̀ тท̂s ПарӨ́́vov). 
Una vez establecido el lugar de Dios, inmóvil, en el noveno cielo, por encima de los demás, Alfonso continúa su exposición con la justificación de todas las creencias de las sectas, atribuyéndoles como causa, generalmente, el error o la ignorancia; sólo en escasísimas ocasiones menciona tímidamente la palabra pecado. Así, por ejemplo, los que aorauan el helemento del agua era ssemeiança del bautismo o los que aorauan a la luna, a Ssanta María queríen aorar ssi lo entendiesen [Ley XLIII]. La misma explicación ofrece con respecto a los signos: De cómmo la ffigura de carnero que dauan al ssigno de Aries, a Ihesu Cristo la deuyeran dar, que es cordero uerdadero de Dios [Ley LV]. Citamos, por último, con el fin de precisar su metodología, un fragmento de la Ley LXVI donde dice: Estos doze ssignos que auemos dicho, segunt el entendimiento spiritual, son estas propriedades que ha en el Padre e en el Ffijo o en el Espíritu Santo, que son tres personas e un Dios. E segunt el tenporal, son los doze apóstoles, así commo dixo Sant Johán euangelista; que assí commo estos doze signos muestran la verdat de los Vii sacramentos de Ihesu Cristo, que fueron puestos e ordenados en Santa Eglesia contra los Vii peccados que los omnes fazen en connoscer las estrellas e aorarlas, que eran ffechuras, e non querien connoscer nin aorar Dios, que las ffiziera.

En esta equiparación que ha efectuado entre los doce signos y los doce apóstoles llega a mencionar la figura de Tolomeo (que en realidad suponemos ha estado utilizando durante toda la exposición) como autoridad máxima del mundo pagano y científico.

Termina Alfonso X el Sabio este tratado exponiendo los Sacramentos si bien no llega al séptimo. La tradición clásica sigue ejerciendo aquí su influencia sobre todo desde el punto de vista léxico como cuando habla de la crisma (Ley LXXXIX): ca crisma tanto quiere dezir en griego commo ungüento sagrado en ssí que ssagra las otras cosas, por citar sólo un ejemplo significativo.

Con lo expuesto hasta ahora queda claro el sistema de funcionamiento del Setenario, su intencionalidad y sobre todo la presencia y carácter del mundo griego cuyos aspectos podemos esquematizarlos de la siguiente forma:

1.- Presencia del léxico griego, etimológicamente analizado por el autor con más o menos acierto, al que el rey Sabio acude como patrimonio indiscutible de cultura, con la idea de que si esta palabra proviene del griego o del latín no admite discusión. 
2.- Presencia de conceptos filosóficos griegos, principalmente cosmológicos, en su mayoría de origen presocrático a los que reintegra en su sistema religioso, confiriéndoles por tanto el valor de divinidades; podríamos decir efectuando una labor remitificadora. La presencia de la filosofía griega también se hace patente a otro nivel y es en el nivel de configuración de la arquitectura del libro, cuyo esqueleto estructurado en siete miembros obedece a una clara influencia pitagórica del valor sagrado del número siete, patente también en el número de los planetas. Dentro de este capítulo de la filosofía griega en el Setenario merece destacarse la figura de Aristóteles (Ley XI) al que el autor cita como criterio de autoridad; por ejemplo, cuando habla de la natura, dice: Et por ende Aristótelis e los otros philósophos ffablaron muy conplidamiente e mostraron por ella todas las cosas, cómmo eran compuestas e ordenadas segunt natura spiritual e tenporal.

3.- Presencia del mito. Cuando hablamos específicamente de presencia del mito, en realidad estamos vinculando el mito y la astrología. Su presencia está clara como hemos visto a lo largo del libro por la gran cantidad de Leyes dedicadas a la exposición de las esferas celestiales, a los planetas y a los signos del zodíaco. Este elemento tiene un precursor evidentemente señalado en Tolomeo cuyas teorías recorren de manera amplia el Setenario, sobrepasando este apartado y constituyendo un elemento común al primero y al segundo, arriba expuestos. Dios en realidad aparece inmerso dentro de este nuevo sistema en el noveno cielo por encima de los planetas y de los signos zodiacales, los rige a todos, acompañado por los doce apóstoles a los que identifica precisamente con estos signos, de forma que los partidarios de la nueva creencia cuando eleven sus ojos al cielo estarán viendo no sólo a los antiguos dioses y héroes de la mitología griega ascendidos a estrellas sino también el reino inmenso del Dios cristiano acompañado por la corte celestial de los doce apóstoles. En realidad, "Cuando cogemos el planisferio celeste y leemos los nombres que en el figuran, Cefeo, Casiopea, Pléyades... una vez más nos damos cuenta de la eternidad de la Mitología griega y romana, tan perenne como las estrellas mismas a las que ha quedado indisolublemente unido su destino... Casi todo el mundo habla del Zodíaco, de Géminis, de Leo, de Tauro, Aries, Cáncer, etc., nombres griegos y latinos que a través de la Mitología o gracias a ella han pasado a formar parte de la cotidianidad incluso de los incultos. Y para qué hablar de los planetas y de los días de la semana con los que doctrinas astrológicas y teosóficas más que la propia 
astronomía han introducido en nuestro haber cultural ni más ni menos que los dioses más importantes de Homero, y Hesíodo o de Virgilio y Ovidio: Saturno, Júpiter, Marte, Venus, Mercurio que con el Sol y la Luna fueron inmortalizados como dioses entre los romanos y que con el curso de la semana han llegado todos o en su mayor parte a nuestros días....

Cuando Arato puso en verso el tratado astronómico de Eudoxo, estaba consagrando definitivamente la divinización griega del cielo, tímidamente iniciada en la literatura griega por Platón. Naturalmente era una exigencia de su tiempo inmortalizar los mitos griegos y convertirlos en Mercurios celestes... como hizo por aquellos años del s. III a. C. Eratóstenes con los "Catasterismos" 21.

Al fin y al cabo Alfonso X procede de la misma forma: mitologiza cristianamente el cielo de la nueva España y se instaura en el fondo él mismo como nuevo rector del universo al identificar las siete letras de su nombre con las siete cualidades de Dios que es la Alfa y la o, Dios en el noveno cielo, Alfonso en el trono real de las tierras españolas, Alfonso, que es también la Alfa y la o porque como sabio abarca en su labor desde el comienzo, desde la cultura griega, simbolizada en la Alfa, hasta la cultura de sus días, simbolizada por la o.

Por lo tanto, y volviendo al principio, diremos que el intento de otorgar un instrumento de unidad jurídica a la España de entonces y cumplir con el añorado deseo del rey Fernando, su padre, se fue convirtiendo en manos del rey Sabio, Alfonso X, en un complejísimo (de ahí la dificultad de su interpretación) y ambiciosísimo entramado cuyos ejes, astrología, filosofía, religión, cultura se hallan sujetos al elemento central que los mueve y que es de naturaleza política. Alfonso X sabe a quiénes se dirige, conoce el poder y la influencia de la Iglesia a la que él mismo pertenece pero no quiere olvidar el pasado; al contrario: quiere integrarlo en su nuevo reino de grandes ambiciones culturales. En suma: ser el rey que supera el pasado conociéndolo. No es mal intento ni tampoco mal ejemplo de la pervivencia del mundo clásico.

${ }^{21}$ Cf. Pérez Jiménez, A. (1998), "Mito y astrología en Grecia: un viaje con retorno", in Religión, Magia y Mitología en la Antigüedad Clásica. Granada: Universidad, 137-8. 
Tradición Clásica y Voluntad Política en el Setenario de Alfonso X el Sabio 163

\section{Bibliografía}

\section{I. - Texto principal:}

VANDERFoRd, K. H. (1984), Alfonso el Sabio, "Setenario". Barcelona: Editorial Crítica.

\section{II. - Fuentes Clásicas}

Aulo Gelio (2006), Noches Áticas. Trad. M. A. Casquero y A. Domínguez García. León: Universidad.

Clemente de Alejandría (1960), Stromata. Ed. O. Stahlin, L. Fruchtel y U. Treu. Berlín: Akademie-Verlag.

Isidoro de Sevilla (2000), Etimologías. Ed. y trad. J. Oroz Reta y M. A. Marcos Casquero. Madrid: B.A.C.

Tolomeo (2001), Tetrabiblos. Ed. F. E. Robbins. Harvard: University Press.

Tolomeo (1998), Almagest. Ed. G. J. Toomer. Princeton: University Press.

\section{III. - Bibliografía secundaria}

KIRK, G. S. y Raven, J. E. (1979), Los filósofos presocráticos. Madrid: Gredos.

LESKY, A. (1976), Historia de la literatura griega. Madrid: Gredos.

Neugebauer, O. (1975), A History of Ancient Mathematical Astronomy. Berlín-Heidelberg-Nueva York.

Pérez Jiménez, A. (1998), "Mito y astrología en Grecia: un viaje con retorno", in José Luis Calvo Martínez (ed.), Religión, Magia y Mitología en la Antigüedad Clásica. Granada: Universidad.

Pérez Jiménez, A. (2009), Paradigmas de nuestra cultura. Astrología y poder político en la Antigüedad. Málaga: Grupo editorial 33. 
